\title{
Chemical Analysis Program for the Time of Flight Mass Spectrometry System
}

\author{
Abdullah Kepceoğlu ${ }^{1}$ and Hamdi Şükür Kilic ${ }^{* 1}$
}

Accepted $3^{\text {rd }}$ September 2016

\begin{abstract}
In this work, we present a computer program that reads, manipulates, analyses and stores the mass spectra obtained by using Laser Time of Flight Mass Spectrometry (L-TOF-MS) system described elsewhere. This program allows users to record the characteristic parameters of experimental data such as vacuum pressure, voltages, laser power, sample name etc. both manually and automatically. Also, the obtained mass spectra can be used to investigate chemical substances $\left(\mathrm{NO}_{\mathrm{x}}, \mathrm{SO}_{\mathrm{x}}\right.$, organic molecules etc.) or can be used to real time identification of the sample differences for given material database (metal oxides, alloys, paintings, healthy and cancerous tissues etc.) by using different mathematical and statistical procedures (PCA, LDA, kNN etc.). We have recently presented a simple chemical analysis procedure by starting from reading raw MS data from oscilloscope using TCP/IP protocol and following data processing steps. We have a great success to reduce the numbers of steps and time duration consumed for the following procedure.
\end{abstract}

Keywords: Mass Spectrometry, Data Acquisition, Data Processing, Statistical Analysis, GUI, MATLAB.

\section{Introduction}

Mass spectrometry is an analytical method and has a wide applications including; industrial quality control [1]-[3], pharmacology [4]-[7], isotope ratio determination [7]-[10] and space exploration researches [11-13]. Mass spectrometers consist of three units, which are an ionisation unit, separation unit and detector. The obtaining and interpretation of the mass spectral data have a great importance to reveal the molecular structure and laser ionisation/dissociation processes [14], [15].

Data analysis is the most time-consuming processes and manual data processing can cause the unintended human error, such as, reading or writing ion intensities, workspace (time - mass to charge ratio) conversion errors. In this work, we have presented the reducing the numbers of steps and time duration spend for the mass spectral analysis procedure.

\section{Background and Theory}

Recent years, multivariate data analysis methods have attracted great attention due to the large experimental data sets obtained from different experimental methods, especially in mass spectrometry, researchers obtain thousands of ion peaks (mass to charge ratio) in different intensities for multiple repetitions for each experiment. Thus, dimension reduction and selection of the data analysis methods (PCA, LDA, kNN etc.) became an important problem. In order to overcome these problems, new software tools was created similar to MCR-ALS (Multivariate Curve Resolution-Alternating Least Squares) toolbox programmed in MATLAB environment [16]. A similar program (FlavonQ) was developed to simultaneously analyse ultra-highperformance liquid chromatography (UHPLC) high-resolution accurate mass spectrometry -mass spectrometry (HRAM-MS) data and UV-VIS spectrometry data in order to profile the

\footnotetext{
${ }^{I}$ Selcuk University Konya/Turkey

* Corresponding Author: Email: hamdisukurkilic@selcuk.edu.tr Note: This paper has been presented at the $3^{\text {rd }}$ International Conference on Advanced Technology \& Sciences (ICAT'16) held in Konya (Turkey), September 01-03, 2016.
}

flavonoids [17]. Recently, a user-friendly program (SIM-XL) was developed for structural protein characterization by using peptide cross-linking analysis method for tandem mass spectrometric data [18].

In proteomics studies, a GUI program (IPeak) also presented for identification of the peptides data obtained from LC-MS/MS method [19]. To identify TLC (Thin Layer Chromatography) information from MSI (Mass Spectrometry Imaging) data sets, a program (DetectTLC) was developed [20]. Homemade software or package programs were used for biological tissue identification [21] or cancer detection [22] by using mass spectrometry data.

\section{Experimental Setup}

Experimental setup consists of laser systems, time of flight mass spectrometer and electronics. In our experiments, we are using high-intensity femtosecond/nanosecond lasers. In the scope of this work, we have used a femtosecond laser system (Quantronix, Integra-C-3.5, NY, USA) as an ionisation source. TOF-MS system was designed and built by our group; background pressure of the vacuum chamber can be pumped down to 10-8 mbar. Ion signals were collected by using an MCP detector (El-Mul Technologies LTD., Israel). The details of the experimental setup were presented elsewhere [23, 24].

Mass spectra were recorded remotely via TCP-IP protocol and real time by using a four-channel oscilloscope (LeCroy Corporation, WaveRunner $64 \mathrm{Xi}, \mathrm{NY}$, USA).

\section{Results and Discussion}

GUI of the mass spectrometry program consists of the subpages that are Experiment, Setup, Connection, Laser Diagnostics and Database Control, as shown in fig. 1. In the experiment section, the user can write sample name, number of sampling and perform plotting mass spectra. Setup section (given as an inset in fig. 1) provides the user to recording experimental parameters such as electrode voltages, vacuum pressure and laser power. In the connection section, the user defines IP number of the oscilloscope 
to connect using TCP-IP protocol. In laser diagnostics section, the user can obtain real-time UV-VIS spectrum of the laser pulses (fig. 2.) by using UV-VIS-NIR portable fiber-optic USB spectrometer (0.1 nm FWHM optical resolution, USB 2000+, Ocean Optics). In database control section, the user can load a database file for given directory from local drivers. The user can control and plot mass spectra for desired rows and each row corresponds to a mass spectrum (fig. 3).

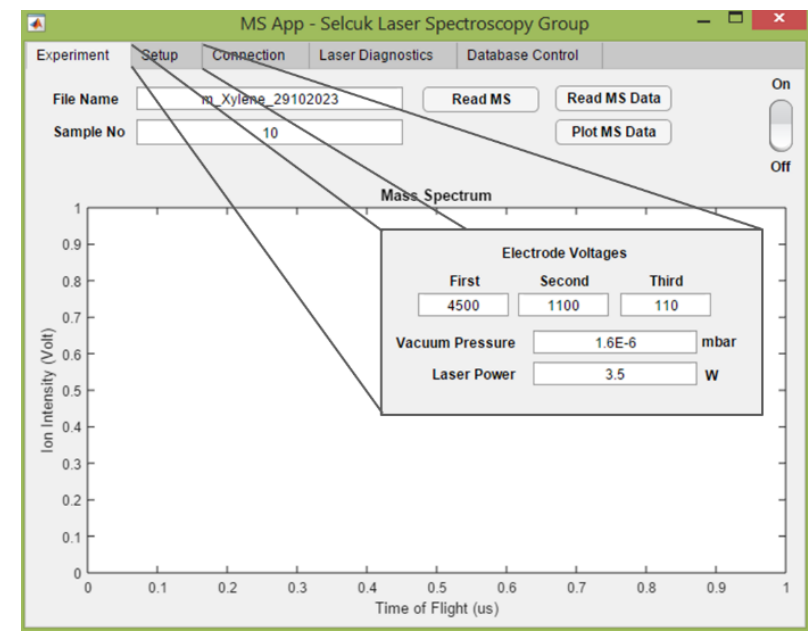

Figure 1. GUI of the MS spectrometry program and subpages; Experiment, Setup, Connection, Laser Diagnostics, Database Control. Setup section presented as an inset.

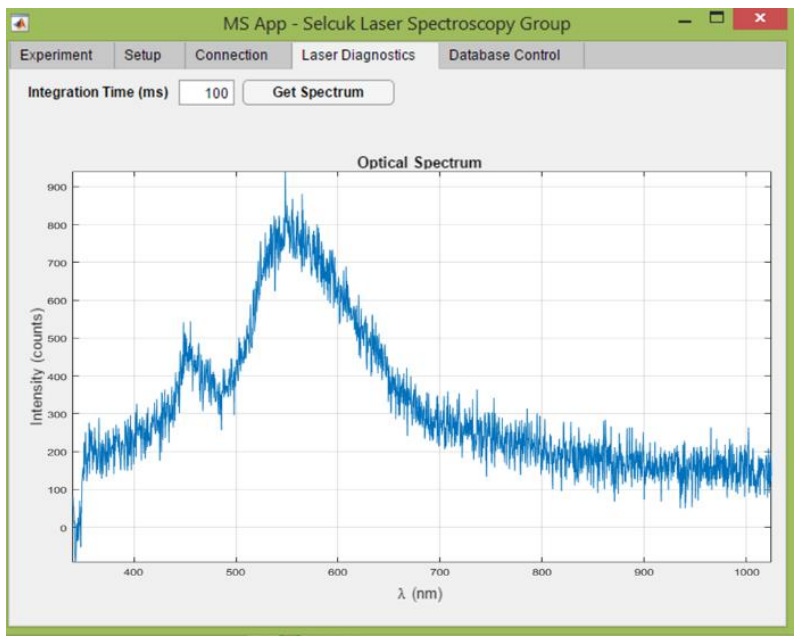

Figure 2. In laser diagnostic section the user can read UV-VIS spectrometer for desired integration time in ms time scale and spectra are plotting real time in the optical spectrum figure area.

In the database control section, the user firstly uses "Load Database" button to and then select database file stored as a MATLAB .mat file. After selecting and opening database file, the program record raw experimental data that contain mass spectra as an ion intensity (intensity corresponds to voltage value read by the oscilloscope) versus the time of flight of the corresponding ion peak. The user has to calibrate the system by using equation $(\mathrm{m} / \mathrm{z})=a t^{2}+b$ to transform time of flight spectrum to mass spectrum to use $\mathrm{m} / \mathrm{z}$ ratio for further spectral analysis [25]. For calibration, the user has to select two known peaks $\left(\mathrm{H}^{+}\right.$and $\mathrm{C}^{+}$or $\mathrm{CH}_{3}{ }^{+}$peaks) to calculate constant $a$ and $b$ to convert all time points to $\mathrm{m} / \mathrm{z}$, ratio. The peak selection on the mass spectrum is shown in fig. 4. The user select first hydrogen ion peak and then carbon ion peak in fig. 4 by using mouse cursor (appearing crosshair).

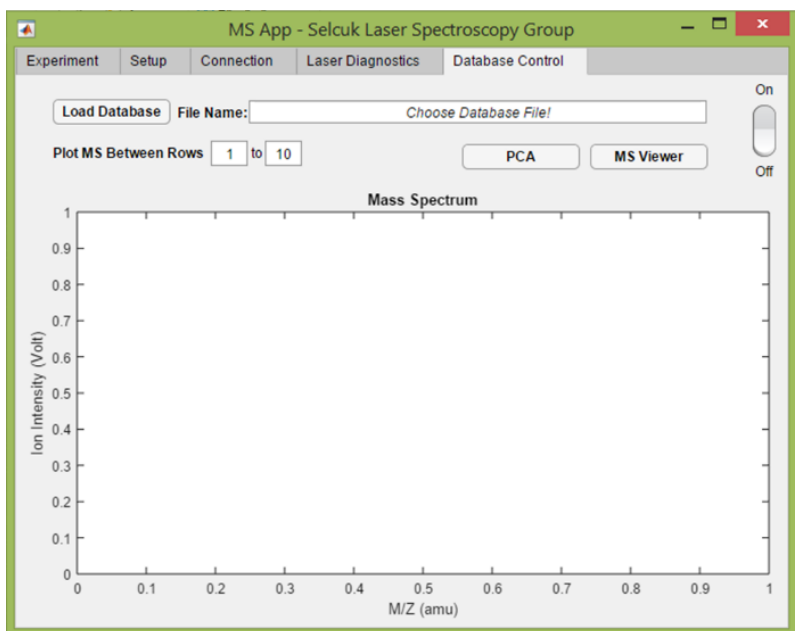

Figure 3. Database control section consists MS viewer button and a statistical analysis button to perform PCA.

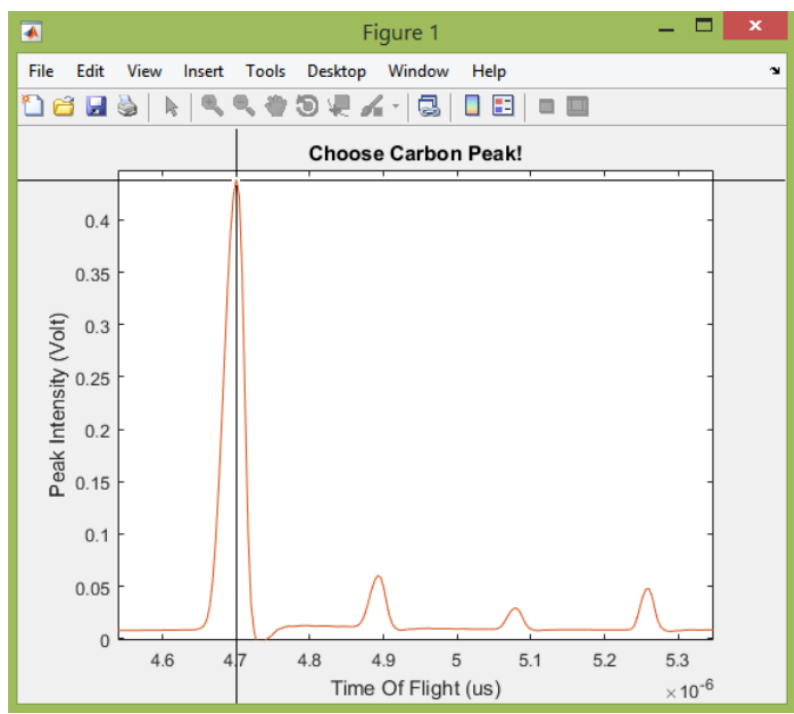

Figure 4. Reference peak selection on the read MS spectra to perform time of flight to mass spectrum transformation.

Following the time of flight spectrum transformation to mass spectrum, the user can view all collected mass spectra by using "MS Viewer" button, the opening window seen in fig. 5. On the other hand, the user can investigate statistical results by using PCA visualization tool as seen in fig. 6 .

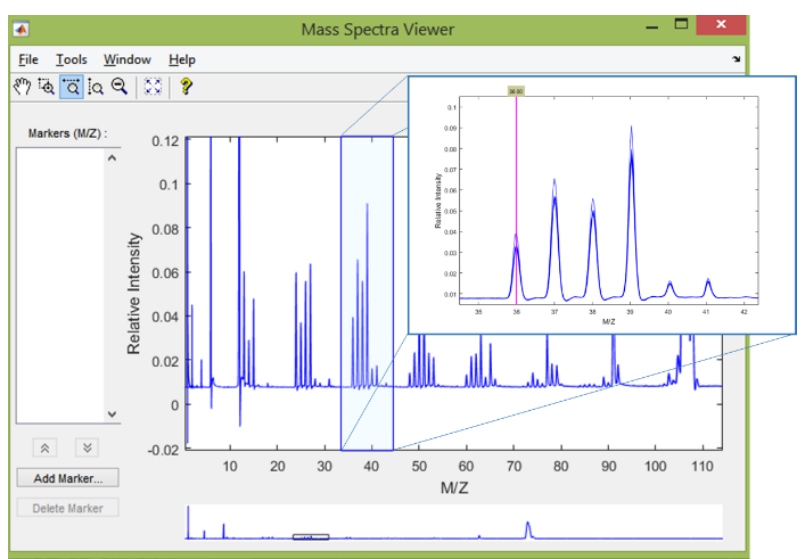

Figure 5. MS Viewer window opens when the user clicks MS Viewer button seen in Fig. 3. The user can select desired peaks to build a marker list into the left-hand side section. 


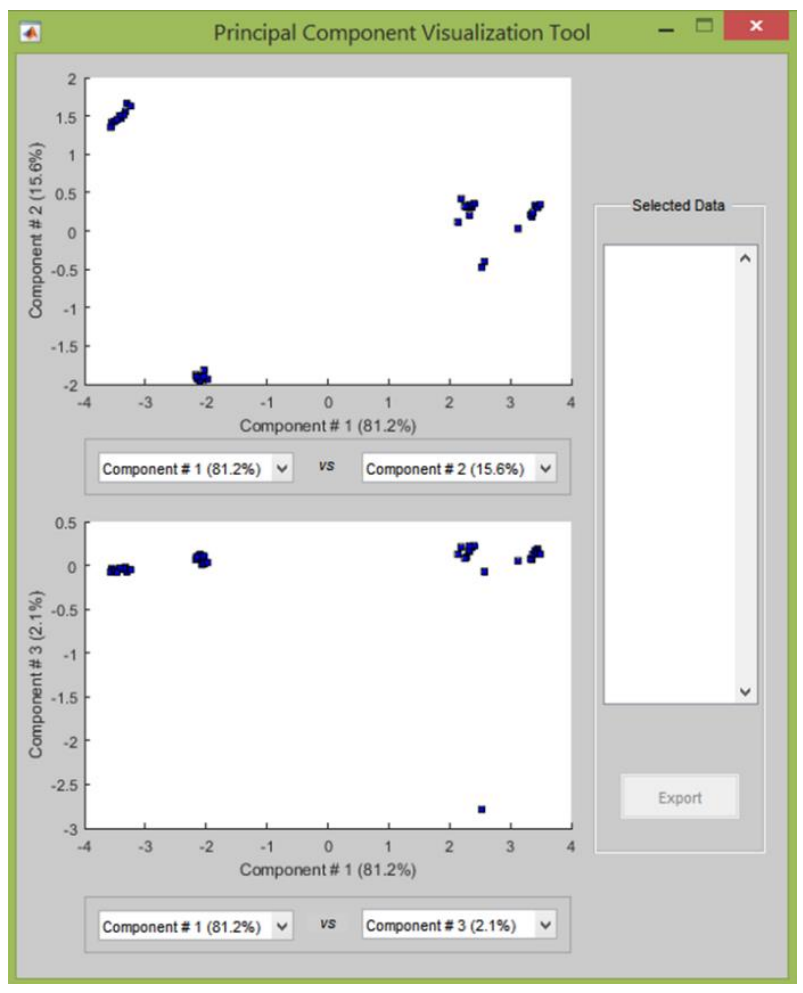

Figure 6. The user can investigate statistical results by using PCA visualization tool.

As a result, the fs-TOF-MS data sets were acquired as raw electronic signals, converted to digital values by using oscilloscope via TCP-IP. The obtained spectra were in the time of flight space first and after calibration, spectra were transformed into mass space.

We have got a great success to reduce the numbers of steps and time duration spend for the manual data processing procedures of the mass spectra analysis from weeks to seconds. Thus, we can eliminate the possibility of the unintended human errors appears in these manual procedures.

Within the context of this work, we built a backbone of the flexible program, which can be manipulated by customs needs, changing experimental setup and/or new unused statistical procedures in laser TOF-MS.

Analysing fs-TOF-MS data using multivariate statistical method, which suggests a new opportunity to use this program in real-time cancer detection research.

\section{Acknowledgements}

This work was supported by the; Scientific and Technical Research Council of Turkey (TUBITAK) under Grant No. 1649B031405880 and Scientific Research Projects Coordination Unit of Selçuk University, Project No. 14201085. Program presented in this article was developed as a part of the $\mathrm{PhD}$ thesis being written by Abdullah Kepcoğlu.

\section{References}

[1] Angeletti, R., Gioacchini, A. M., Seraglia, R., Piro, R., \& Traldi, P. (1998). The potential of matrix-assisted laser desorption/ionization mass spectrometry in the quality control of water buffalo mozzarella cheese. J Mass Spectrom, 33(6), 525-531. doi:10.1002/(SICI)10969888(199806)33:6<525::AID-JMS655>3.0.CO;2-S

[2] Balog, J., Szaniszlo, T., Schaefer, K.-C., Denes, J., Lopata,
A., Godorhazy, L., . . . Toth, M. (2010). Identification of biological tissues by rapid evaporative ionization mass spectrometry. Analytical Chemistry, 82(17), 7343-7350.

[3] Balsiger, H., Altwegg, K., Bochsler, P., Eberhardt, P., Fischer, J., Graf, S., . . . Wollnik, H. (2007). Rosina Rosetta orbiter spectrometer for ion and neutral analysis. Space Science Reviews, 128(1-4), 745-801. doi:10.1007/s11214-006-8335-3

[4] Berman, E. S., Levin, N. E., Landais, A., Li, S., \& Owano, T. (2013). Measurement of $\delta 18 \mathrm{O}, \delta 17 \mathrm{O}$, and $17 \mathrm{O}$-excess in water by off-axis integrated cavity output spectroscopy and isotope ratio mass spectrometry. Analytical Chemistry, 85(21), 10392-10398.

[5] Briois, C., Thissen, R., Thirkell, L., Aradj, K., Bouabdellah, A., Boukrara, A., . . . Colin, F. (2016). Orbitrap mass analyser for in situ characterisation of planetary environments: Performance evaluation of a laboratory prototype. Planetary and Space Science, 131, 33-45.

[6] Brouwers, E. E., Tibben, M., Rosing, H., Schellens, J. H., \& Beijnen, J. H. (2008). The application of inductively coupled plasma mass spectrometry in clinical pharmacological oncology research. Mass Spectrom Rev, 27(2), 67-100. doi:10.1002/mas.20159

[7] Bruins, A. (1994). Atmospheric-pressure-ionization mass spectrometry: II. Applications in pharmacy, biochemistry and general chemistry. TrAC Trends in Analytical Chemistry, 13(2), 81-90.

[8] Catharino, R. R., Milagre, H. M. S., Saraiva, S. A., Garcia, C. M., Schuchardt, U., Eberlin, M. N., . . . de Souza, V. (2007). Biodiesel typification and quality control by direct infusion electrospray ionization mass spectrometry fingerprinting. Energy \& Fuels, 21(6), 3698-3701. doi:10.1021/ef7003078

[9] Cheng, H., Edwards, R. L., Shen, C. C., Polyak, V. J., Asmerom, Y., Woodhead, J., . . A Alexander, E. C. (2013). Improvements in Th-230 dating, Th-230 and U-234 halflife values, and U-Th isotopic measurements by multicollector inductively coupled plasma mass spectrometry. Earth and Planetary Science Letters, 371, 82-91. doi:10.1016/j.epsl.2013.04.006

[10] Chu, N. C., Taylor, R. N., Chavagnac, V., Nesbitt, R. W., Boella, R. M., Milton, J. A., . . . Burton, K. (2002). Hf isotope ratio analysis using multi-collector inductively coupled plasma mass spectrometry: an evaluation of isobaric interference corrections. Journal of Analytical Atomic Spectrometry, 17(12), 1567-1574. doi:10.1039/b206707b

[11] Cordeau, E., Arnaudguilhem, C., Bouyssiere, B., Hagege, A., Martinez, J., Subra, G., . . . Enjalbal, C. (2016). Investigation of Elemental Mass Spectrometry in Pharmacology for Peptide Quantitation at Femtomolar Levels. Plos One, 11(6), e0157943. doi:ARTN e0157943

[12] 10.1371/journal.pone.0157943

[13] Cotter, R. J. (1994). Time-of-flight mass spectrometry. Paper presented at the Time-of-Flight Mass Spectrometry.

[14] Dietrich, P., \& Corkum, P. B. (1992). Ionization and Dissociation of Diatomic-Molecules in Intense InfraredLaser Fields. Journal of Chemical Physics, 97(5), 31873198. doi:Doi 10.1063/1.463006

[15] Gündoğdu, Y., Kepceoğlu, A., Kılıç, H. Ş., Akbaş, M., Doğan, M., \& Ledingham, K. W. (2014). Femtosaniye Laser Pulsları Yardımıyla $\mathrm{Cn}+(\mathrm{n}=1 \ldots$ 60) Topak İyonlarının Hem C60 Hemde Grafit Hedefler Kullanılarak 
Ayrı Ayrı Üretimi ve Ölçümü (021101)(1-9). Afyon Kocatepe Üniversitesi Fen Ve Mühendislik Bilimleri Dergisi, 14(2).

[16] Jaumot, J., Gargallo, R., de Juan, A., \& Tauler, R. (2005). A graphical user-friendly interface for MCR-ALS: a new tool for multivariate curve resolution in MATLAB. Chemometrics and intelligent laboratory systems, 76(1), 101-110. doi:10.1016/j.chemolab.2004.12.007

[17] Kaddi, C. D., Bennett, R. V., Paine, M. R., Banks, M. D., Weber, A. L., Fernandez, F. M., \& Wang, M. D. (2016). DetectTLC: Automated Reaction Mixture Screening Utilizing Quantitative Mass Spectrometry Image Features. J Am Soc Mass Spectrom, 27(2), 359-365. doi:10.1007/s13361-015-1293-9

[18] Kepceoğlu, A., Gündoğdu, Y., Ledingham, K. W. D., \& Kilic, H. S. (2016). Identification of the isomers using principal component analysis (PCA) method. Paper presented at the AIP Conference Proceedings.

[19] Lima, D. B., de Lima, T. B., Balbuena, T. S., NevesFerreira, A. G. C., Barbosa, V. C., Gozzo, F. C., \& Carvalho, P. C. (2015). SIM-XL: A powerful and userfriendly tool for peptide cross-linking analysis. Journal of proteomics, 129, 51-55.

[20] Lindinger, W., Hansel, A., \& Jordan, A. (1998). On-line monitoring of volatile organic compounds at pptv levels by means of proton-transfer-reaction mass spectrometry (PTRMS) - Medical applications, food control and environmental research. International Journal of Mass Spectrometry, 173(3), 191-241. doi:Doi 10.1016/S01681176(97)00281-4

[21] Palmer, P. T., \& Limero, T. F. (2001). Mass spectrometry in the US space program: Past, present, and future. Journal of the American Society for Mass Spectrometry, 12(6), 656-675. doi:Doi 10.1016/S1044-0305(01)00249-5

[22] Posthumus, J. (2004). The dynamics of small molecules in intense laser fields. Reports on Progress in Physics, 67(5), 623.

[23] Volkening, J., Walczyk, T., \& Heumann, K. G. (1991) Osmium Isotope Ratio Determinations by Negative Thermal Ionization Mass-Spectrometry. International Journal of Mass Spectrometry and Ion Processes, 105(2), 147-159. doi:Doi 10.1016/0168-1176(91)80077-Z

[24] Wen, B., Du, C., Li, G., Ghali, F., Jones, A. R., Kall, L., . . Wang, J. (2015). IPeak: An open source tool to combine results from multiple MS/MS search engines. Proteomics, 15(17), 2916-2920. doi:10.1002/pmic.201400208

[25] Zhang, M., Sun, J., \& Chen, P. (2015). FlavonQ: An Automated Data Processing Tool for Profiling Flavone and Flavonol Glycosides with Ultra-High-Performance Liquid Chromatography-Diode Array Detection-High Resolution Accurate Mass-Mass Spectrometry. Analytical Chemistry, 87(19), 9974-9981. 